\title{
Analisando a colaboração e produção científica da área ensino e pesquisa em Administração e Contabilidade
}

\author{
Henrique César Melo Ribeiro \\ http://orcid.org/0000-0002-0704-1812 \\ I Universidade do Delta do Parnaíba, PI, Brasil. \\ Professor Adjunto.
}

http://dx.doi.org/10.1590/1981-5344/3915

O objetivo deste estudo foi analisar a colaboração e produção científica da área ensino e pesquisa em administração e contabilidadenos períodos de 2007, 2009, 2011, 2013 e 2015. A metodologia utilizada contou com as técnicas de análise bibliométrica e de rede social 1mode e 2-mode.Constatou-se alta centralidade nas redes de coautoria e das instituições, realçando os atoresGilberto José Miranda e a USP. As redes two-mode corroboraram com as redes 1-mode, enfatizando a importância e relevância das instituições e dos temas abordados nesta pesquisa. As redes 2modecontribuírampara manifestar a envergadura das instituições, e a tendência dos temas divulgados na academia, impactando diretamente para melhor entender e compreender como as redes de colaboração e a produção científica da área Ensino e Pesquisa em Administração e Contabilidade são difundidas $e$ socializadas na academia.

Palavras-chave:Produção científica; Ensino e pesquisa em administração e contabilidade; Bibliometria; Rede one-mode; Rede two-mode. 


\section{Analyzing the collaboration and scientific production of the teaching and research area in Administration and Accounting}

The objective of this study was to analyze the collaboration and scientific production of the teaching and research area in administration and accounting in the periods of 2007, 2009, 2011, 2013 and 2015. The methodology used included the techniques of bibliometric an alysis and social network 1-mode and 2-mode. High centrality was found in co-authoring networks and institutions, high lighting the actors Gilberto José Miranda and USP. Two-mode networks corroborated with 1-mode networks, emphasizing the importance and relevance of the institutions and the themes addressed in this research. The 2-mode networks havecontributedto show the magnitude of the institutions and the tendency of the themes divulged in the academy, directly impacting to understand and understand how the networks of collaboration and the scientific production of the area of Education and Research in Administration and Accounting are disseminated and socialized in academia.

Keywords: Scientific production;Teaching and research in administration and accounting; Bibliometria; One-mode network; Two-mode network.

Recebido em 17.03.2019 Aceito em 15.06.2020

\section{Introdução}

O processo de análise da colaboração e produção científica (BULGACOV; VERDU, 2001; PARREIRASet al., 2006; SAMPAIO et al., 2015) é relevante para as Instituições de Ensino Superior (IES) e para os seus professores/pesquisadores delas oriundos (FERREIRA; FALASTER, 2016; ALMEIDA; GRÁCIO, 2019). E neste sentido, tal processo e 
relevância podem ser visto sob duas óticas: (i) prestação de contas do professor/pesquisador para com a sociedade que financia o estudo científico; (ii)troca de informações e conhecimentos entre acadêmicos e suas respectivas IES, mediante os diversos meios de comunicação (CORREIA; ALVARENGA; GRACIA, 2012).

Ao realizar uma pesquisa científicae comunicar seus resultados na academia, os autores nativos de suas respectivas instituições, estão exercendo açõesnecessárias e primordiais para o alargamento, difusão, disseminação e socialização dos saberes científicos. (CORREIA; ALVARENGA; GRACIA， 2012; MAIA; CARVALHO-FREITAS, 2015)em qualquercampodo conhecimento científico (BUFREMet al., 2007), como por exemplo,na Administração (BERTERO; CALDAS; WOOD JR., 1999) e na Contabilidade (LEITE FILHO, 2008).

Reitera-se que uma pesquisa científica pode ser comunicada de duas maneiras: formal ou informal (CORREIA; ALVARENGA; GRACIA, 2012). Os meios formais são as revistas científicas (SANTOS; REJOWSKI, 2013). E, os meios informais são eventos científicos (LIMA LEITE, 2007). No que se refere aos eventos científicos, destacam-se no contexto nacional: EnANPAD (Encontro da Associação Nacional de Pós-Graduação e Pesquisa em Administração), ANPTUR (Associação Nacional de Pesquisa e PósGraduação em Turismo), ANPCONT (Associação Nacional de Programas de Pós-Graduação em Ciências Contábeis), CCC-USP (Congresso USP de Controladoria e Contabilidade) dentre outros (PINHEIRO, 2016).

Sendo que cada um destes eventos científicos fica em realce em suas respectivas áreas do conhecimento, ou seja, Administração, Contabilidade e Turismo.No que tange a área de gestão (FERREIRA et al., 2018), e no que se refere aos eventos mais relevantes de cada área, enfatiza-se o EnANPAD, que é o principal responsável pela publicação da produção científica de Administração (PARENTE; FISCHER, 2014; SILVA; MELO; MUYLDER, 2015), sendo, portanto, considerado o congresso científico de maior importância da referida área (SILVA; CARVALHO NETO, 2012). Salienta-se que o citado evento é realizado pela ANPAD (Associação Nacional de Pós-Graduação e Pesquisa em Administração) (QUINTELLA, 2003).

Além do EnANPAD, existem outros eventos científicos, que são promovidos e realizados pela ANPAD, são eles: Encontro de Marketing(EMA), Encontro de Estudos Organizacionais (EnEO), Encontro de Estudos em Estratégia (3Es), Simpósio de Gestão da Inovação Tecnológica (Simpósio), Encontro de Administração Pública e Governança (EnAPG), Encontro de Gestão de Pessoas e Relações de Trabalho (EnGPR),Encontro de Administração da Informação (EnADI), Encontro de Ensino e Pesquisa em Administração e Contabilidade(EnEPQ) (BALSANet al., 2016). 
Neste panorama fica em evidencia o EnEPQ, que é um evento científico que acontece a cada dois anos, e sua primeira edição ocorreu em 2007 (FARIA; FIGUEIREDO, 2013). Tem o objetivo de alargar e robustecer a discussão e a difusão do conhecimento sobre Ensino e Pesquisa em Administração e Contabilidade no Brasil e é promovido pela ANPAD (SOUSA; RODRIGUES JÚNIOR; COELHO, 2017).O próprio EnANPAD também tem uma divisão que foca no Ensino e Pesquisa em Administração e Contabilidade (SERVA, 2016), mas para este estudo o foco será apenas o EnEPQ.

Existem trabalhos científicos nacionais que já enfatizaram a produção científica da área Ensino e Pesquisa em Administração e ou Contabilidade(SOUZAet al., 2008; LORDSLEEM; ARAÚJO, 2009; WALTERet al., 2009;ESPARTELet al., 2011; LOURENÇOet al., 2012;MIRANDAet al., 2013; RIBEIRO, 2013;VENDRUSCOLO; BEHAR, 2014;BOLZAN; ANTUNES, 2015;SCHMITZet al., 2015FERREIRA; MALAQUIAS, 2016; RIBEIRO, 2017). Porém, nenhum destes estudos analisou a colaboração e produção científica da área ensino e pesquisa em administração e contabilidade sob a ótica do EnEPQ nos períodos de 2007, 2009, 2011, 2013 e 2015.

Surge assim o objetivo e a justificativa deste estudo.Isto posto, considerando as arguições reunidas, desenvolveu-se, fazendo emergir a questão de pesquisa que norteou o presente estudo: Qual o perfil e as características de colaboração e produção científica da área ensino e pesquisa em administração e contabilidade sob a ótica do EnEPQ nos períodos de 2007, 2009, 2011, 2013 e 2015? E para mensurar as informações, conhecimentos e os saberes científicos registrados, adotarse-ão a bibliométria (BUFREM; PRATES, 2005) e a rede social (PESSOA ARAÚJOet al., 2017).A realização deste trabalho é em decorrência do mesmo adotar técnicas de análise bibliométrica e de rede social (ALVARADO; ARANGO, 2018), sendo que está ultima focou nas redes onemode e two-mode (CRUZ et al., 2011).

Com isso, esta investigação alinhavará e contribuirá de maneira macro para: (i) melhor entender e compreender como os artigos publicados até aqui no EnEPQ colaboraram para ampliar e disseminar a referida área na academia; (ii)fazer surgir dados, informações e conhecimento contemporâneos sobre a área em análise, influenciando, consequentemente na concretização de grupos de estudo, ou quem sabe, no surgimento destes novos grupos, ou no aperfeiçoamento dos mesmos nos Programas de Pós-Graduação StrictoSensu em Administração e ou Contabilidade ou nas Graduações de ambas as áreas do saber, impactando no alargamento e fortalecimento do Ensino e Pesquisa em Administração e Contabilidade (EPAC) na literatura científica no Brasil; (iii) disseminar aplicações de redes de dois modos, em virtude do Brasil ainda 
existir poucos estudos publicados que mencionamouempregam aplicações de Análise de Rede Sociais de dois modos (TOMAÉL; MARTELETO, 2013).

\section{Ensino e pesquisa em Administração e Contabilidade}

O ensino faz parte do tripé dasIES no Brasil (MARTINS; ZERBINI, 2014) e a profissão de pesquisador vincula-se à profissão de docente (ANDRIOLA; SULIANO, 2015), notadamente nas áreas de Administração (MELO; SERVA, 2014) e Contabilidade (MIRANDAet al., 2013).Neste enfoque, constata-se a relação direta que existe entre o ensino e a pesquisa, sobretudo no cenário dos Programas de Pós-Graduação Stricto Sensunos campo de estudos (LEITE FILHO; MARTINS, 2006) Administração (GUIMARÃESet al., 2009) e Contabilidade (COMUNELOet al., 2012).

Neste diapasão, realça-se o ensino em administração que tem o objetivo de repassar a pratica e o conhecimento da gestão na formação dos profissionais da área (FESTINALLI, 2005; NASSIF; GHOBRIL; BIDO, 2007; GODOYet al., 2009) e, analogamente, tem as nuances do ensino em contabilidade que é de promover o desenvolvimento de conhecimentos e habilidades que permitam ao profissional do campoadentrar no mercado de trabalho (LEMES; MIRANDA, 2014; LARAet al., 2017). Ambos respaldados em especial, pelos seus respectivos cursos de graduação (MEDEIROS; BORGES; LEAL, 2009; MOTTA; QUINTELLA, 2012).

Isto posto, versa-se a pesquisa em Administração, queaglutina conhecimentos interdisciplinares, e, portanto, pode ser publicada em revistas científicas de outras áreas do saber (SERRA; FERREIRA; CUNHA, 2017), incorrendo em uma maior discussão de seus princípios e em sua aplicabilidade nas organizações (PIERANTI, 2008; ABBAD; CORRÊA; MENESES, 2010). Já a pesquisa em contabilidade passa pelo estudo do conhecimento e da aplicabilidade dessa ciência (COSTA; FONSECA, 2018) possuindotambém características interdisciplinares (MENDONÇA NETO; RICCIO; SAKATA, 2006), contudo, é relativamente recente no contexto nacional (GOMES; LEMES, 2016).

Diante disso, afloram-se os estudos focados ao ensino e pesquisa em Administração, que desempenham respeitável papel no alargamento do conhecimento desta área (ODELIUS; SENA, 2009).Consente um maior entendimento e compreensão do processo de formação discente, como também indicameios para adequá-lo às demandas, ininterruptamente em mutação, estabelecidas pela sociedade (COSTA, 2008). No que tange ao ensino e a pesquisa em contabilidade, quando articuladas entre si e de maneira reciproca, se tornam enriquecedoras e preponderantes para articular, construir e ampliar novos conhecimentos e saberes científicos, 
impactando na transformação das organizações no âmbito social (WALTERet al., 2009).

Faz-se surgir então a área do Ensino e Pesquisa em Administração e ou Contabilidade na academia, por meio de eventos científicos, ajudando assim a melhor entender e compreender no bojo da referida área, todas as nuances que a norteiam. Eventos como o EnANPAD, ANPCONT, CCCUSP e o EnEPQ alargam, robustecem, disseminam e socialização pesquisas voltadas a este campo do saber, influenciando diretamente em sua performance, crescimento e maturação na literatura científica brasileira (SOUZAet al., 2008;MIRANDAet al., 2013; SCHMITZet al., 2015).

Diante do revelado, entende-se, compreende-se e justifica-se o porquê da área Ensino e Pesquisa em Administração e ou Contabilidade sersistemicamentediscutida na literatura científicabrasileira (SOUZAet al., 2008; LORDSLEEM; ARAÚJO, 2009; WALTERet al., 2009; ESPARTELet al., 2011; LOURENÇOet al., 2012; MIRANDAet al., 2013; RIBEIRO, 2013; VENDRUSCOLO; BEHAR, 2014; BOLZAN; ANTUNES, 2015; SCHMITZet al., 2015; FERREIRA; MALAQUIAS, 2016; RIBEIRO, 2017).

Contudo, afirma-se que nenhuma destas focou em analisar a colaboração eprodução científica da área ensino e pesquisa em administração e contabilidade sob a ótica do EnEPQ nos períodos de 2007, 2009, 2011, 2013 e 2015, por meio da bibliometria, e das redes onemode e two-mode. Diante do fato narrado, o presente artigo vislumbra-se importante para academia, se fazendo assim justificável sua realização por evidenciar dados, informações e conhecimentos científicos atualizados do campo em ênfase, contribuindo a posteriori para seu alargamento, fortalecimento e evolução na literatura científica brasileira.

\section{Procedimentos metodológicos}

A questão de pesquisa que alicerça o presente estudo é: Qual o perfil e as características de colaboração e produção científica da área ensino e pesquisa em administração e contabilidade sob a ótica do EnEPQ nos períodos de 2007, 2009, 2011, 2013 e 2015? Para se responder a citada questão, utilizou-se as técnicas de análise bibliométrica (LEITE FILHO, 2008; CASSUNDÉ; CASSUNDÉ JUNIOR, 2012), e de rede social (OLIVEIRA e SILVAet al., 2006), sendo que está última enfatizará além da tradicional 1-mode, a não tão usual na academiaa rede 2-mode (TOMAÉL; MARTELETO, 2013).

A bibliometria é utilizada para se mencionar a análises de cunho matemático e estatístico (MOMESSO; NORONHA, 2017) no que concerne a explorar, investigar, mapear, padrões, perfis e características de estudos científicos publicados (CRUZet al., 2011; TOMOMITSU; CARVALHO; MORAES, 2017) sejam em periódicos científicos (SANTOS; REJOWSKI, 
2013; CAVALCANTI JÚNIOR; FERRAZ, 2013) e ou eventos acadêmicos (RIBEIRO, 2017).Em relação a bibliometria, salienta-se que esta é embasada (TEIXEIRA; IWAMOTO; MEDEIROS, 2013) pelas Leis de: Bradford (produtividade dos periódicos científicos) (ALVARADO, 2016), Lotka (produtividade dos autores) (URBIZAGASTEGUI, 2008; CÂNDIDOet al., 2018), Price (elite dos autores) (PESSOA ARAÚjOet al., 2017) e Zipf (frequência das palavras-chave) (ARAÚJO; SANSÃO; YEHIA, 2016). Ressalta-se que para este estudo, as leis enfatizadas serão as de Lotka e de Price, sendo que esta última é um aprimoramento da Lei de Lotka (ALVARADO, 2002).

Já as redes sociais são interaçõesnativas da rede de cooperação (ROSSONI; GUARIDO FILHO, 2007),constituídas pelos agentes sociais no ambiente em que estão inseridos (ROSSONI; GUARIDO FILHO, 2009). Mediante estas conexões é possível alargar e concretizar pensamentos, ideias, conhecimentos dasações de pesquisa científica e de produção acadêmica conjunta nas visualizações das Figuras das redes dos autores e IESde um modo (GUIMARÃESet al., 2009; NASCIMENTO; BEUREN, 2011) e de dois modos (ROSSONI; HOCAYEN-DA-SILVA, 2008; TOMAÉL; MARTELETO, 2013).

Versa-se que para esta investigação foram enfocados alguns atributos/características de rede social, como: nós, laços, densidade e centralidade (RIBEIRO; SANTOS, 2015; ALVARADO; ARANGO, 2018), sobretudo, a centralidade de grau (degree) e a centralidade de intermediação (MELLO; CRUBELLATE; ROSSONI, 2010).O presente trabalho colocará em evidencia também as redes two-mode. A rede twomode é uma matriz assimétrica (retangular) (LATHABAI; PRABHAKARAN; CHANGAT, 2017), na qual cada célula determina o volume de ocorrências de compartilhamento em conjunto entre os atores (GUARIDO FILHO; MACHADO-DA-SILVA; GONÇALVES, 2010). As redes 2-mode possibilitam ao estudiosoobservar a maneira com que atores e entidades estão relacionados e, constatando assim, que as entidades criam ligações entre os atores e, por sua vez, os atores criam vínculos entre as entidades(TOMAÉL; MARTELETO, 2013).Neste contexto, uma das informações contempladas no presente estudo é arquitetara vinculação entre autores e IES como um único sistema social, isto é, em uma mesma rede social (TOMAÉL; MARTELETO, 2013; BARBOSA; LADEIRA; VICENTE, 2017).

\subsection{Procedimentos de coleta e análise de dados}

Foi realizada uma coleta de dados em investigaçõespublicadas nos períodos de 2007, 2009, 2011, 2013 e 2015 no EnEPQ. Os dados foram coletados da ANPAD (http://www.anpad.org.br/ anpad/). Este procedimentoatendeu identificar 520publicaçõesevidenciadasnosperíodos 
que foram realizados o evento EnEPQ. Foi realizada a análise dos dados por meio os seguintes indicadoresbibliométricos e de rede de 1-mode e 2mode: (i) Autores + redes de coautoria; (ii) IES + rede social das instituições; (iii) Redes de coautoria: degree + betweenness; (iv) Redes das IES: degree + betweenness; ( $v$ ) Rede two-mode (autores e artigos) + rede two-mode (autores e instituições); e(vi) Temas abordados + rede two-mode (autores e temas). Estes indicadores foram calculados, capturados e visualizados, usando os softwares UCINET 6e NetDraw for Windows e Microsoft Excel 2007.

\section{Análise e discussão dos resultados}

Esta seção contemplará a análise e discussão dos resultados em 520 estudos científicos publicados nos eventos do EnEPQ realizados até o presente momento.

\subsection{Autores + redes de coautoria}

A Figura 1.1 e a Figura 1.2evidenciamrespectivamente, o perfil de produtividade dos autores (LEITEFILHO, 2008), e a sua respectiva rede de coautoria (ESPARTELet al., 2011) formando a colaboração científica (FERREIRA et al., 2018), da presente investigação.

Figura 1.1: Autores

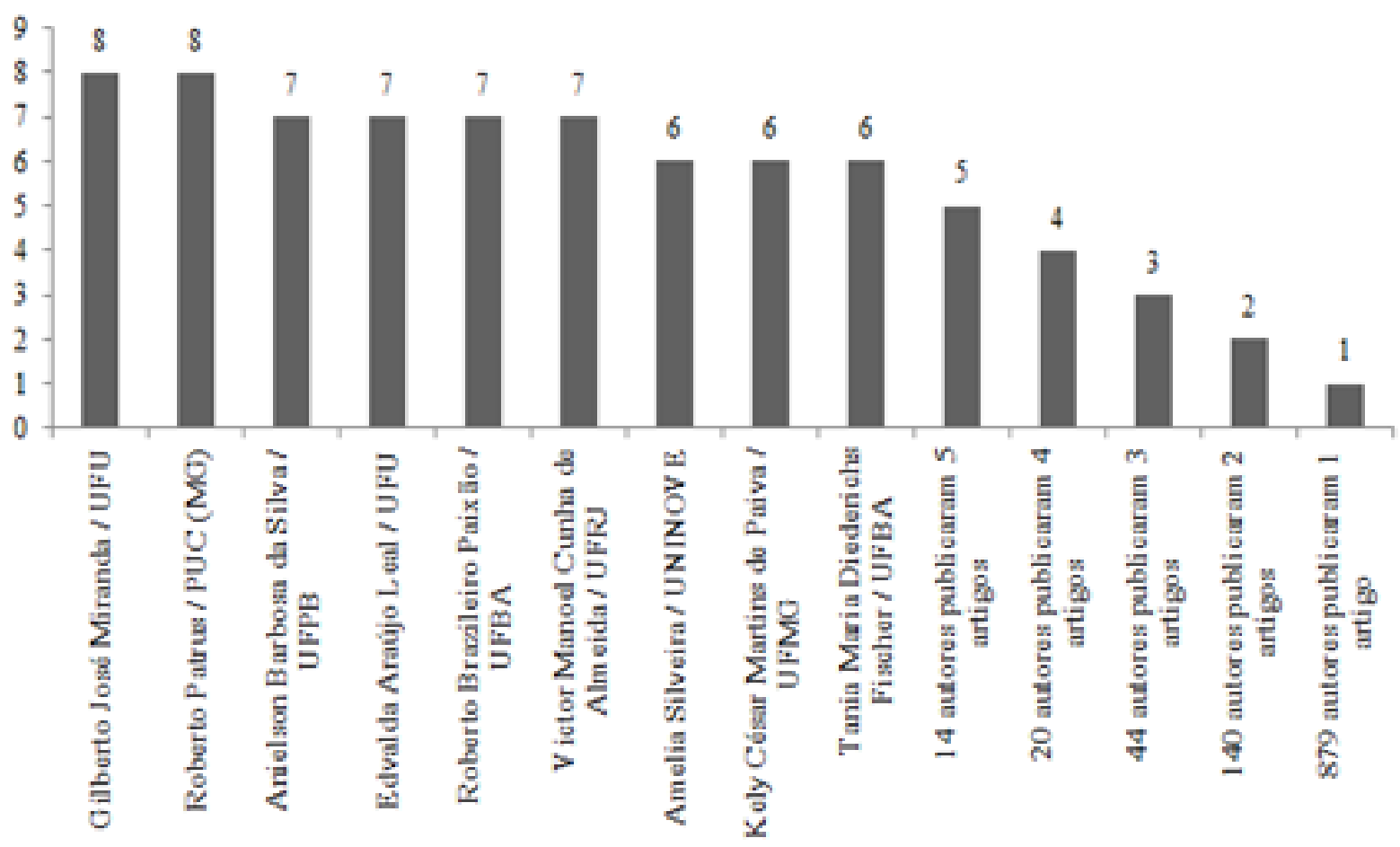

Fonte: Dados da pesquisa

A Figura 1.1 coloca em destaque os 1.106 autores identificados neste estudo, em dois panoramas: (i) enfatizando a produtividade, em 
especial dos nove mais acentuados; (ii) a rede dos 1.106 pesquisadores. Nisso, observam-se que os docentes/estudiosos: Gilberto Miranda, Roberto Patrus, Anielson da Silva, Edvalda Leal, Roberto Paixão, Victor de Almeida, Amelia Silveira, Kely de Paiva e Tania Fischer foram os mais profícuos desta investigação.Pela Lei de Price os referidos autores compõem a "elite" das publicações (PESSOA ARAÚjOet al., 2017) na área de Ensino e Pesquisa em Administração e Contabilidade sob a ótica do EnEPQ. Ribeiro (2017) corrobora com os achados desta seção, em especial no que tange aos autores Gilberto José Miranda eEdvalda Araújo Leal como os mais prolíferos na linha de pesquisa educação e pesquisa em contabilidade à luz da ANPCONT de 2007 a 2016.

Figura 1.2: Redes de coautoria

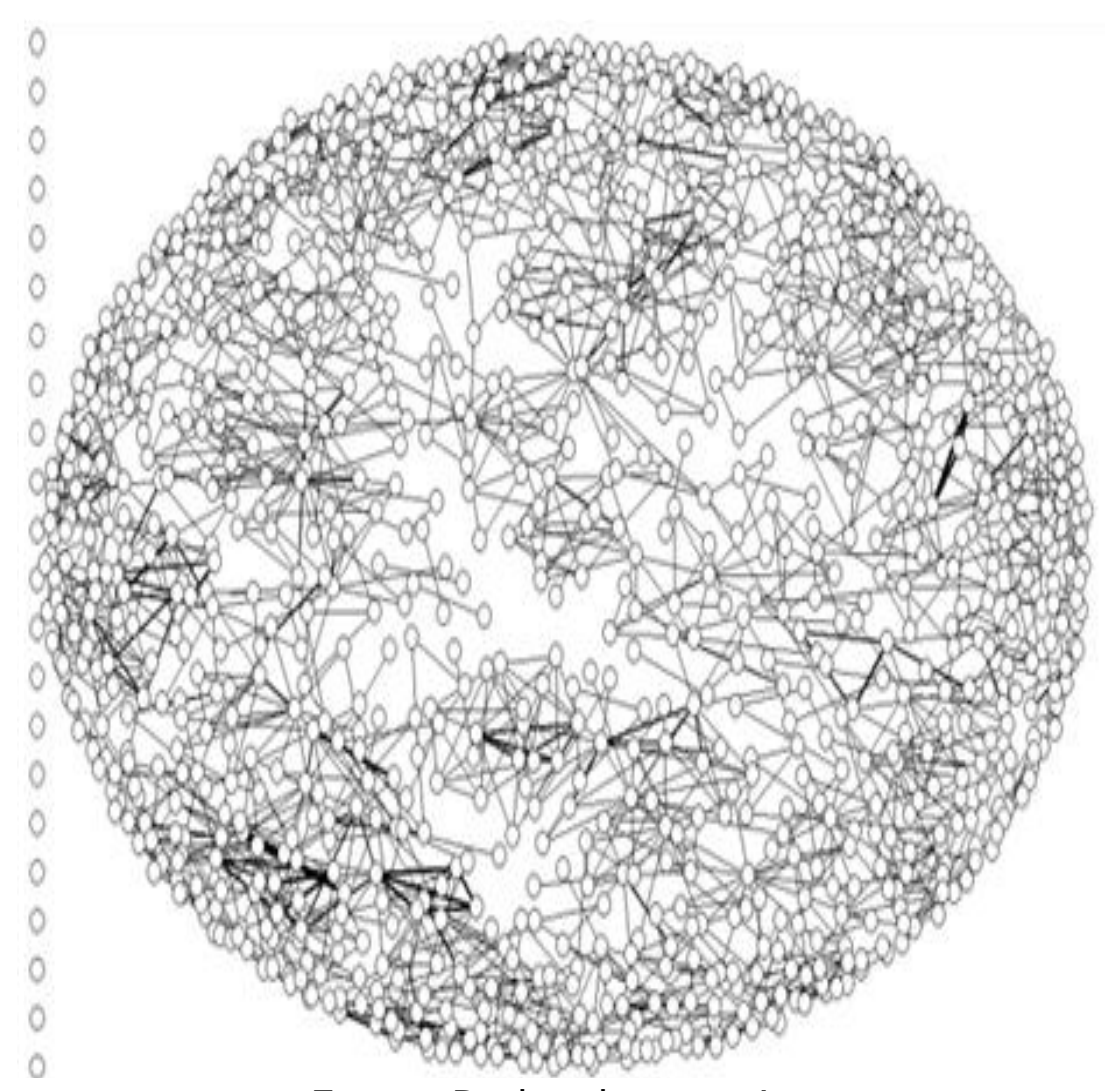

Fonte: Dados da pesquisa

Ainda cabe enfocar que 78 pesquisadores publicaram de três a cinco estudos. 140 autores divulgaram duas investigações. E, 879 investigadores evidenciaram somente uma pesquisa cada. Surge a Lei de Lotka a qual enfatiza a produtividade dos autores (CÂNDIDOet al., 2018), e, enseja que poucos pesquisadores publicam muito e que muitos autores publicam pouco (RIBEIRO, 2013). Neste sentido, salienta-se quea colaboração científica (FERREIRA et al., 2018) é aqui concebida pela rede 
de coautoria deste trabalho (Figura 1.2),manifestada aqui pelos 1.106 nós (professores/pesquisadores), conectados entre si, partilhando a autoria de um artigo, e, consequentemente a informação e conhecimento científico (OLIVEIRA e SILVAet al., 2006), representado aqui pelo Ensino e Pesquisa em Administração e Contabilidade.

\subsection{IES + rede social das instituições}

A Figura 2.1 e a Figura 2.2 contemplam respectivamentea produtividade das IES e a rede social das IES (GUIMARÃESet al., 2009) da presente pesquisa.

Figura 2.1: IES

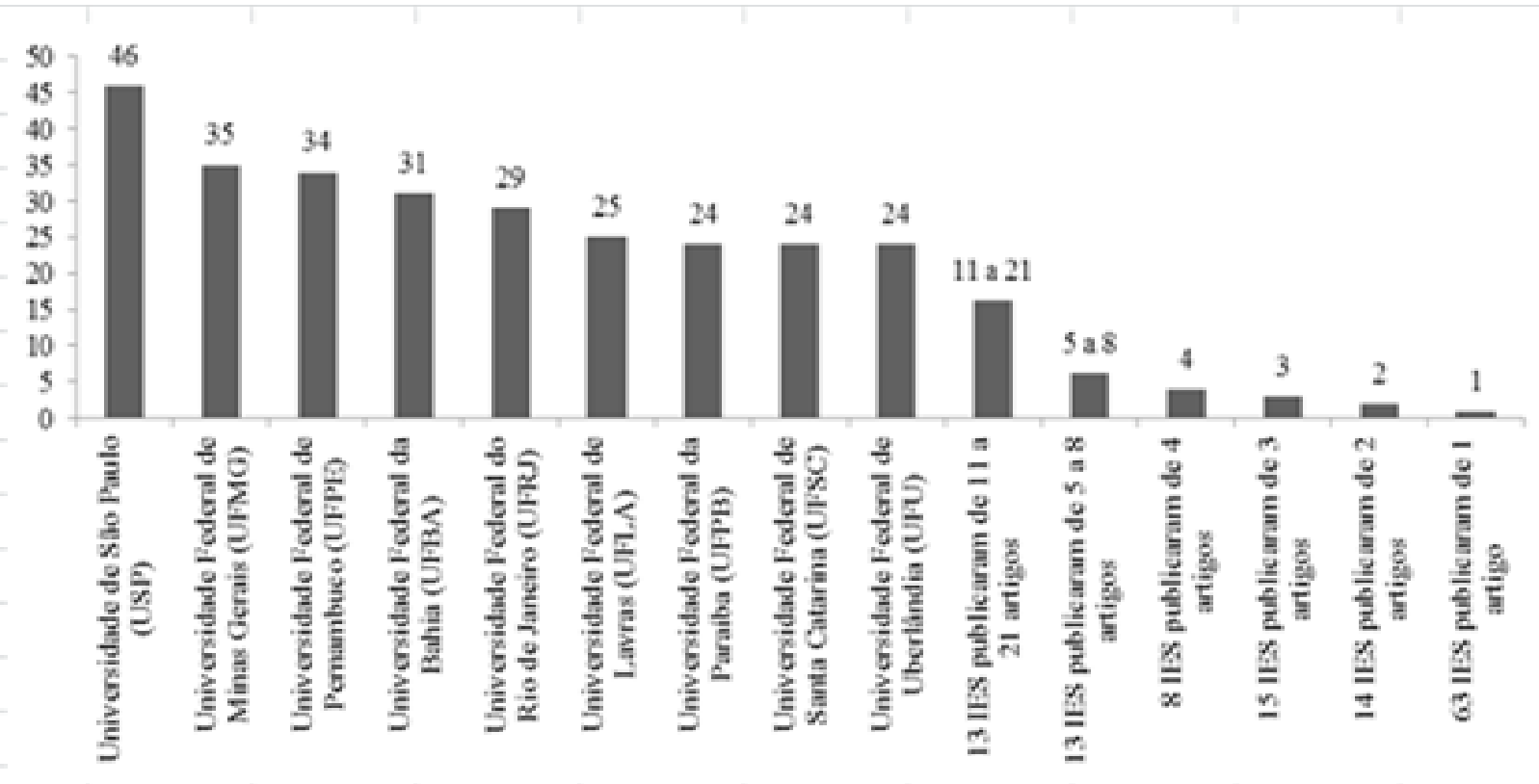

Fonte: Dados da pesquisa

É destacada a USPcomo a IES mais produtiva deste trabalho, sob a ótica das publicações divulgadas no EnEPQ até aqui. Afloram-se também as instituições: UFMG, UFPE, UFBA, UFRJ, UFLA, UFPB, UFSC e UFU. Em investigações similares a esta, os autores Souza et al. (2008), Walter et al. (2009), Espartel et al. (2011), Lourenço et al. (2012), Ribeiro (2013) e Ribeiro (2017) corroboram com os achados desta seção, sobretudo, em relação a USP. 
Figura 2.2: Rede social das instituições

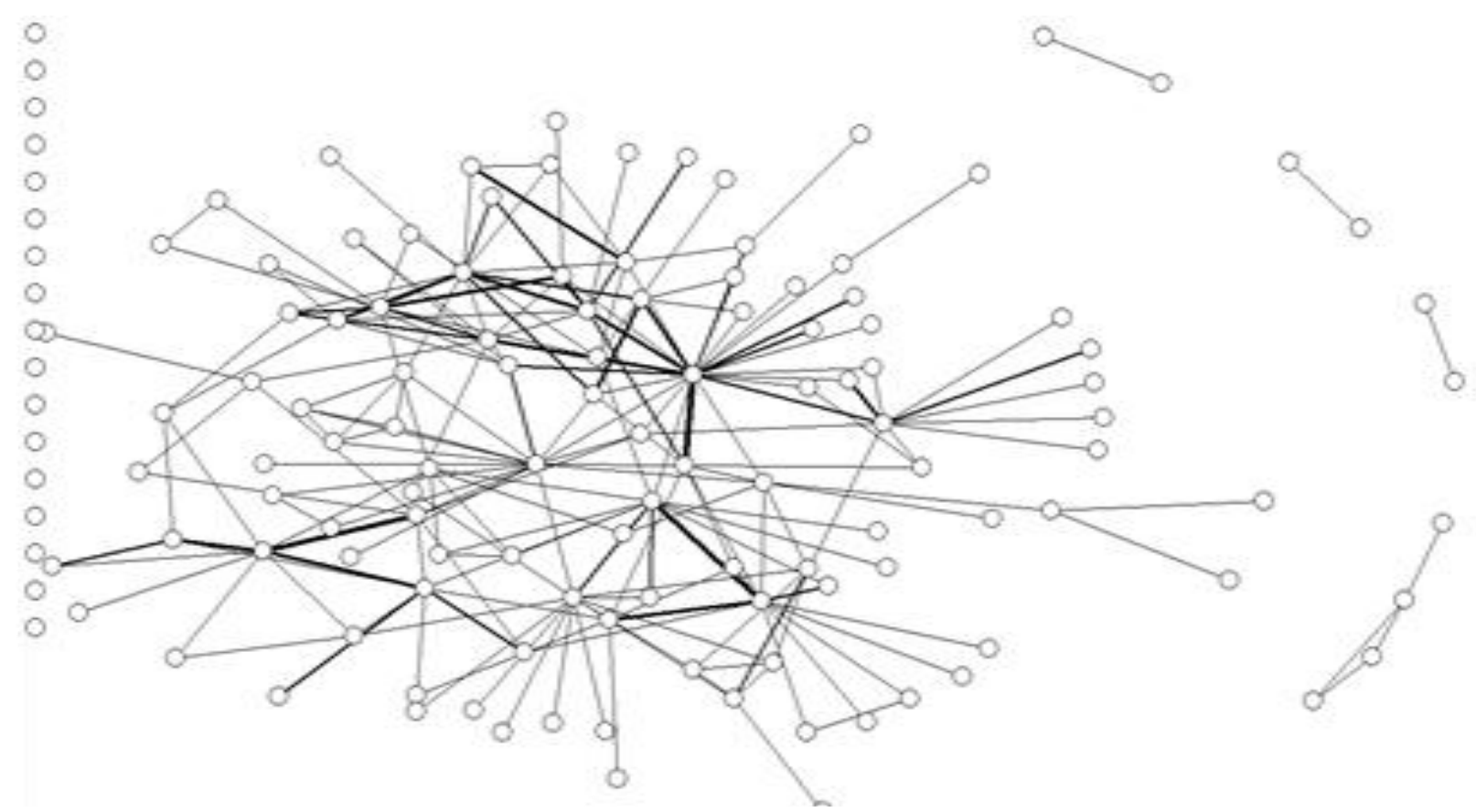

Fonte: Dados da pesquisa

De maneira geral, a produtividade das IES, mediante seus respectivos Programas de Pós-Graduação Stricto Sensu (ROSSONI; GUARIDO FILHO, 2009; NASCIMENTO; BEUREN, 2011; COMUNELOet al., 2012), e, por meio de seus grupos de estudos, faz surgir e publicar pesquisas sobre a área em análise, tornando-as (As IES) as mais prolíferas e relevantes do Brasil, à luz do EnEPQ, influenciando diretamente no fomento e difusão da cooperação científica (PARREIRASet al., 2006), que aqui se faz representada pelos 135 nós das 135 IES que se conectam; e produção acadêmica, contribuindo para o alargamento, disseminação e socializaçãodo conhecimento científico da mencionada área na academia.

\subsection{Redes de coautoria: degree + betweenness}

A Figura 3 visualiza da esquerda para a direita,a rede de coautoria (degree) e a rede de coautoria (betweenness). Entende-se que a centralidade de grau demonstra o número de ligações que um ator (ROSSONI; GUARIDO FILHO, 2009), no caso os autores, possui com os demais pesquisadores da rede. Neste estudo enfatizam-se: Gilberto Miranda, Edvalda Leal, Victor de Almeida, Maria José Domingues, ClériaLourenço, Maria Pessoa, Augusto Cabral, João Nascimento, Sidnei 
Marinho, Cíntia Medeiros, Kely de Paiva e Roberto Paixão. Sendo que destes estudiosos, cinco estão entre os mais prolíferos nesta investigação.

Já o betweenness corresponde a um ator (pesquisador para este estudo) intermediário, que se vincula a outros atores que diretamente não se interagem entre si. Com isso, tais atores detêm um papel preponderante dentro da estrutura da rede (MELLO; CRUBELLATE; ROSSONI, 2010). Isto posto, versam-se os principais estudiosos intermediários desta investigação: Isabel da Silva, Mônica Cappelle, Késia Silva e Cléria Lourenço. Neste painel, vislumbra-se a autora Cléria Donizete da Silva Lourenço como a mais central deste estudo, tanto no degree como no betweenness. Contudo, a autora em destaque não aparece como uma das mais profícuas deste trabalho.

É interessante notar que, apesar de alguns pesquisadores surgirem como os mais produtivos nesta análise, não se destacam como investigadores centrais. Tal característica pode ser devido ao perfil de autoria das publicações e, consequentemente a parceria das mesmas, influenciando diretamente nos nós e laços que os pesquisadores como autores principais tem com seus parceiros (coautores).

Figura 3: Redes de coautoria: degree + betweenness
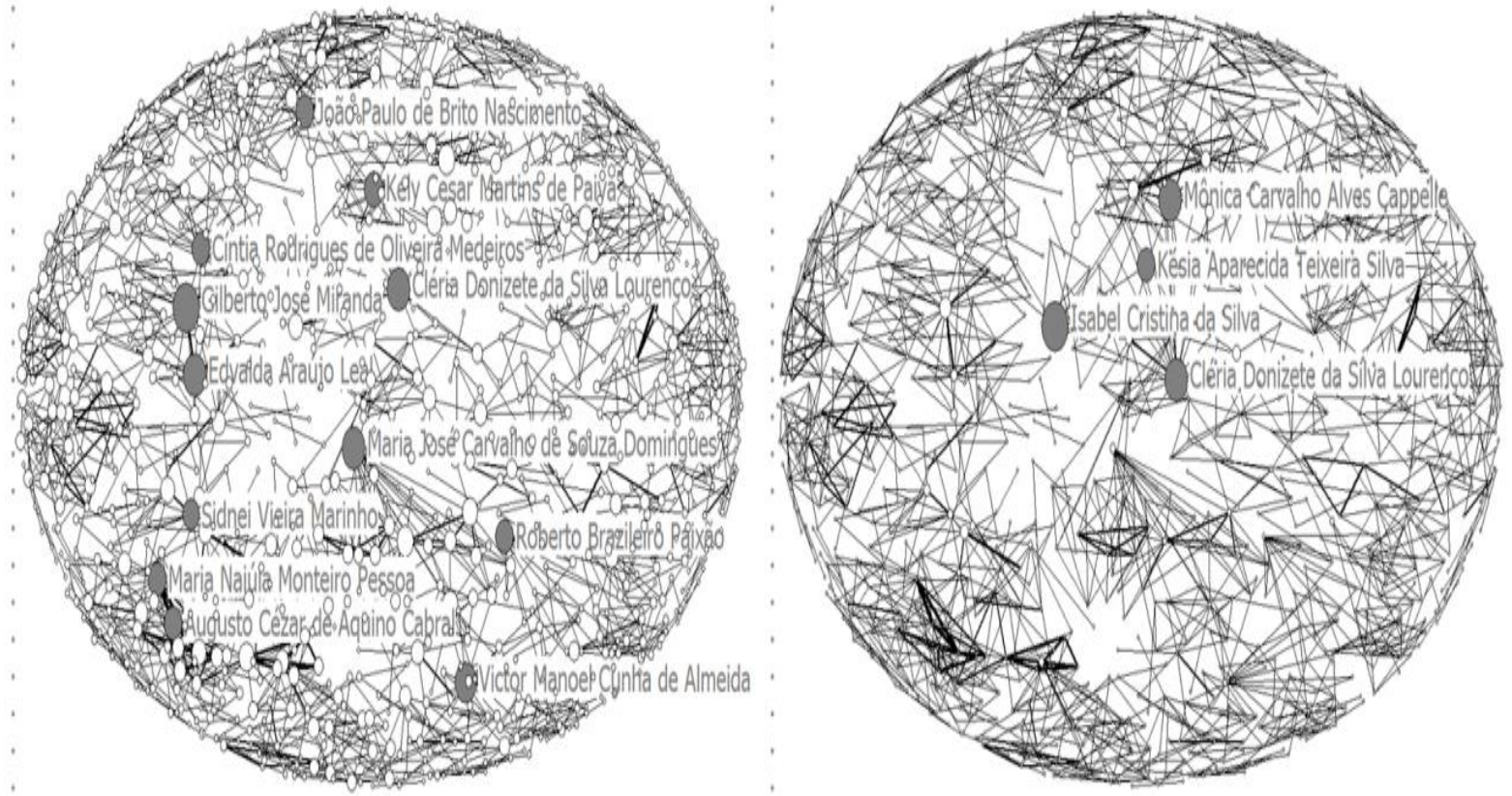

Fonte: Dados da pesquisa

Em suma, ser o mais profícuo em um determinado estudo científico longitudinal, como é o caso deste, não o habilita para ser um investigador central, salvo, o mesmo consiga interagir com outros autores (parceiros) em " $n$ " publicações, e, ou realizem parcerias intermediando divulgações 
com outros estudiosos, contribuindo com isso para sua proficuidade e, concomitantemente para seu realce na centralidade de grau e ou de intermediação (WALTER et al., 2009;MELLO; CRUBELLATE; ROSSONI, 2010; RIBEIRO, 2013; RIBEIRO, 2017).

\subsection{Redes das IES: degree + betweenness}

A Figura 4vislumbra da esquerda para a direita a rede das IES, colocando em relevo a centralidade de grau e a de intermediação respectivamente.Em relação à centralidade de grau, que indica o número de colaborações de uma determinada IES (ROSSONI; GUARIDO FILHO, 2007), verificou-se que a USP foi a mais central. Ela é seguida pelas instituições: UFRGS, UFPE, FURB, UFLA, UFMG e UFBA. Em relação às instituições com maior centralidade de intermediação, constata-se que estas contribuem para maior homogeneização do campo científico em análise, estimulando a troca de experiências, informações e conhecimentos ao mesmo tempo em que mantêm sua conexão (ROSSONI; GUARIDO FILHO, 2007).

Neste contexto, afloram-se as IES: USP, UFRGS, UFMG, UFPE, UFLA e UFBA. Diante disso, é plausível dizer que uma IES que está globalmente centralizada em uma rede social, pode significar afirmar que ela está proporcionalmente mais próxima de todas as outras IES da rede (ROSSONI; GUARIDO FILHO, 2007).Perante a afirmação, é coerente colocar em realce a USP como a instituição mais central, profícua, importante e relevante para o processo de colaboração científica (SAMPAIO et al., 2015) da produção acadêmica da área Ensino e Pesquisa em Administração e Contabilidade, sob a ótica do EnEPQ, influenciando com isso em sua difusão, disseminação e socialização no contexto literário científico nacional. Podem ser enfatizadas também as instituições: UFMG, UFPE, UFBA e UFLA.

Isto posto, afirma-se que a centralidade das IES tem relação direta com sua respectiva produção científica (ROSSONI; GUARIDO FILHO, 2009). Os achados desta seção, são confirmados de maneira análoga nas investigações dos autores Souza et al. (2008), Walter et al. (2009), Espartelet al. (2011), Lourenço et al. (2012), Ribeiro (2013) e Ribeiro (2017). 
Figura 4: Redes das IES: degree + betweenness
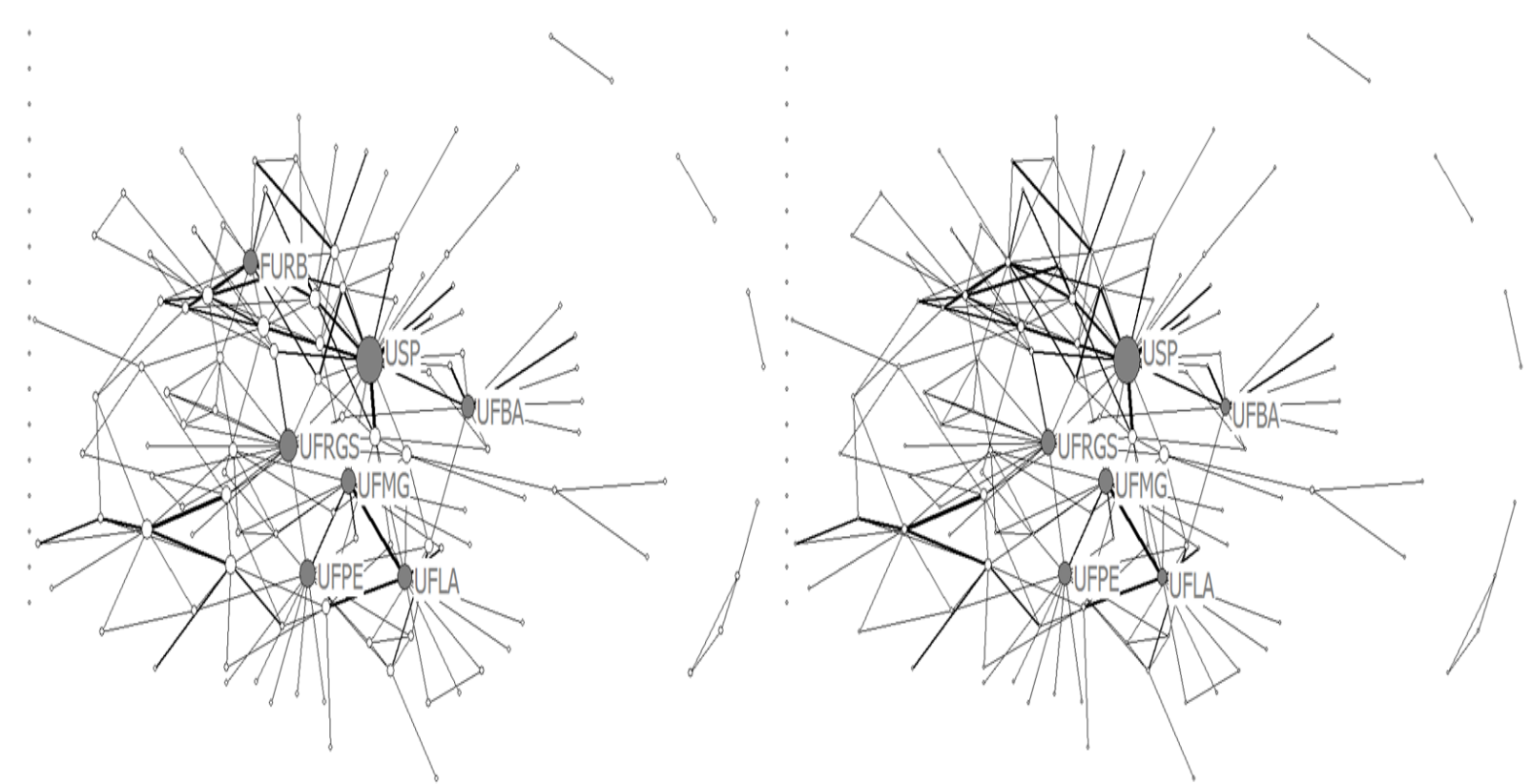

Fonte: Dados da pesquisa

\subsection{Redetwo-mode (autores e artigos) + rede two-mode (autores e instituições)}

Da esquerda para a direita, a Figura 5 coloca em destaque duas redes de dois modos, a primeira enfocando a rede conjunta dos autores com os seus respectivos artigos; e a segunda é a rede conjunta dos autores e das IES. 
Figura 5: Rede two-mode (autores e artigos) + rede two-mode (autores e instituições)
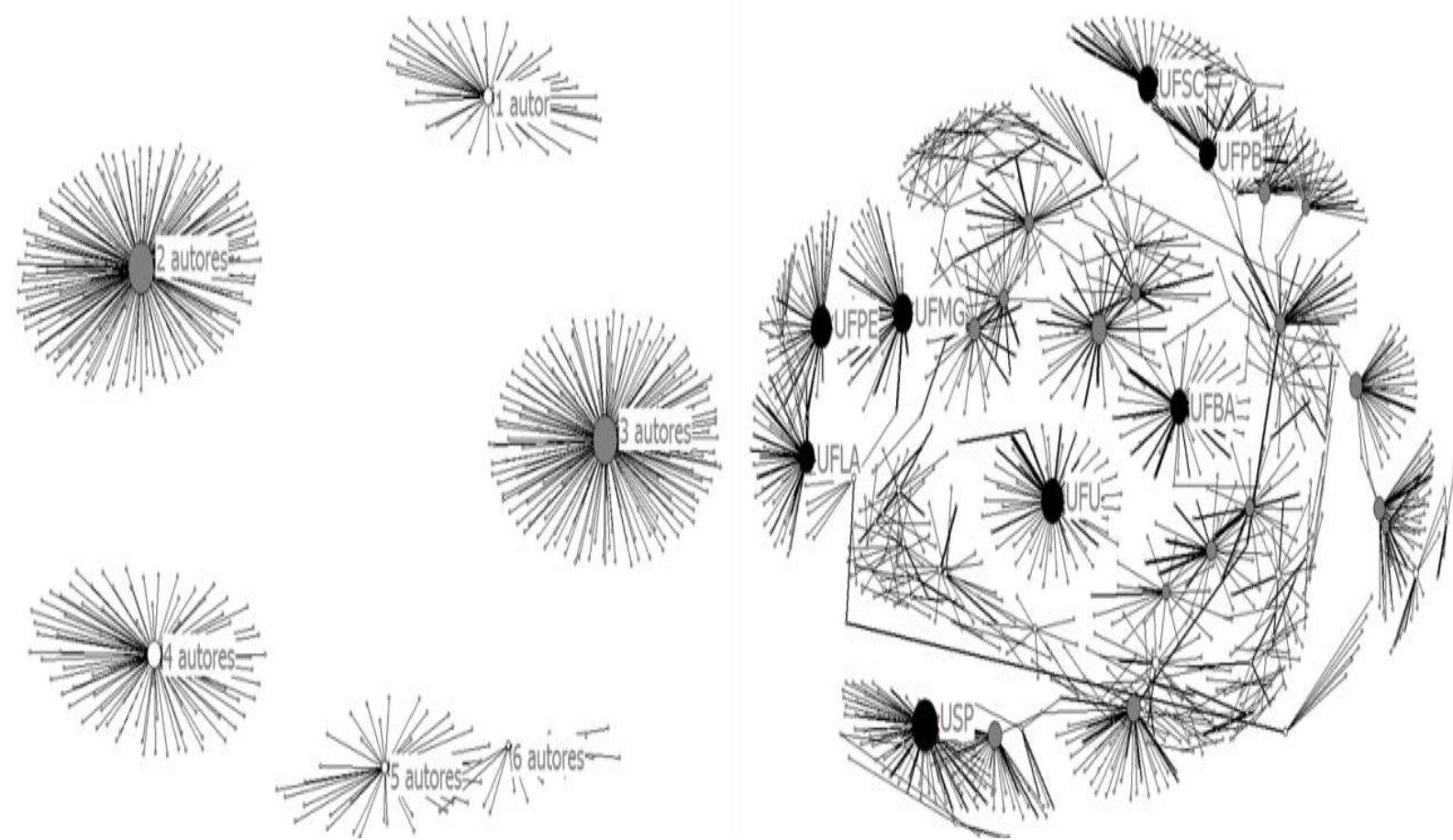

Fonte: Dados da pesquisa

Entende-se que os grupos de estudos permitem um alargamento de publicações de artigos em parceria (RIBEIRO; SANTOS, 2015). Tal ação é visualizada nas redes de coautoria, cuja maioria dos participantes costuma divulgar seus estudos em conjunto com outros pesquisadores (BULGACOV; VERDU, 2001). Diante disso, por meio da rede 2-modeque relaciona os pesquisadores com seus respectivos estudos (MELLO; CRUBELLATE; ROSSONI, 2010), contempla-se a Figura 5 (lado esquerdo), onde mostra que neste presente estudo, houve predominância de artigos publicados em parceria.

Ainda analisando as características de autoria evidenciadas na Figura 5 (lado direito), agora enfocando a outra rede 2-mode entre os autores e suas respectivas afiliações (IES) (ROSSONI; HOCAYEN-DASILVA, 2008; TOMAÉL; MARTELETO, 2013), destacam-se as instituições: USP, UFU, UFSC, UFMG, UFPE, UFBA, UFPB e UFLA. Compondo quatro IES da região Sudeste, três instituições da região Nordeste e uma da região Sul do Brasil. Informação esta corrobora similarmente por Lordsleem e Araújo (2009). Todas estas estão entre as nove instituições que mais publicaram trabalhos sobre a área Ensino e Pesquisa em Administração e Contabilidade. 
Contudo, somente cinco destas, também ficaram em evidencia no atributo centralidade de grau e de intermediação: USP, UFMG, UFPE, UFBA e UFLA.Confirmando assim a envergadura, importância e relevância destas IES em relevo para a colaboração científica e produção acadêmica da área em análise, e, concomitantemente para os temas dela nativos, sejam eles embrionários, emergentes, maduros ou legitimados na academia, influenciando e contribuindo a posteriori para o alargamento, difusão e disseminação destes na academia, impactando e cooperando na robustez e evolução do campo científico em investigação.

\subsection{Temas abordados + rede two-mode (autores e temas)}

A Figura 6.1 e a Figura 6.2 visualizam respectivamente os temas abordados e a rede conjunta dos autores e dos temas. Contemplam-se os temas mais publicados nesta pesquisa (Figura 6.1): caso de ensino, formação discente, educação a distância, ensino em administração, ensino-aprendizagem, estratégias de aprendizagem, pesquisa científica em administração, estratégia empresarial, estudos organizacionais, pósgraduação stricto sensu em administração, empreendedorismo, formação docente, responsabilidade social, competências acadêmicas, pesquisa científica em contabilidade e administração pública. Estas informações são confirmadas analogamente por Vendruscolo e Behar (2014).

Figura 6.1:Temas abordados

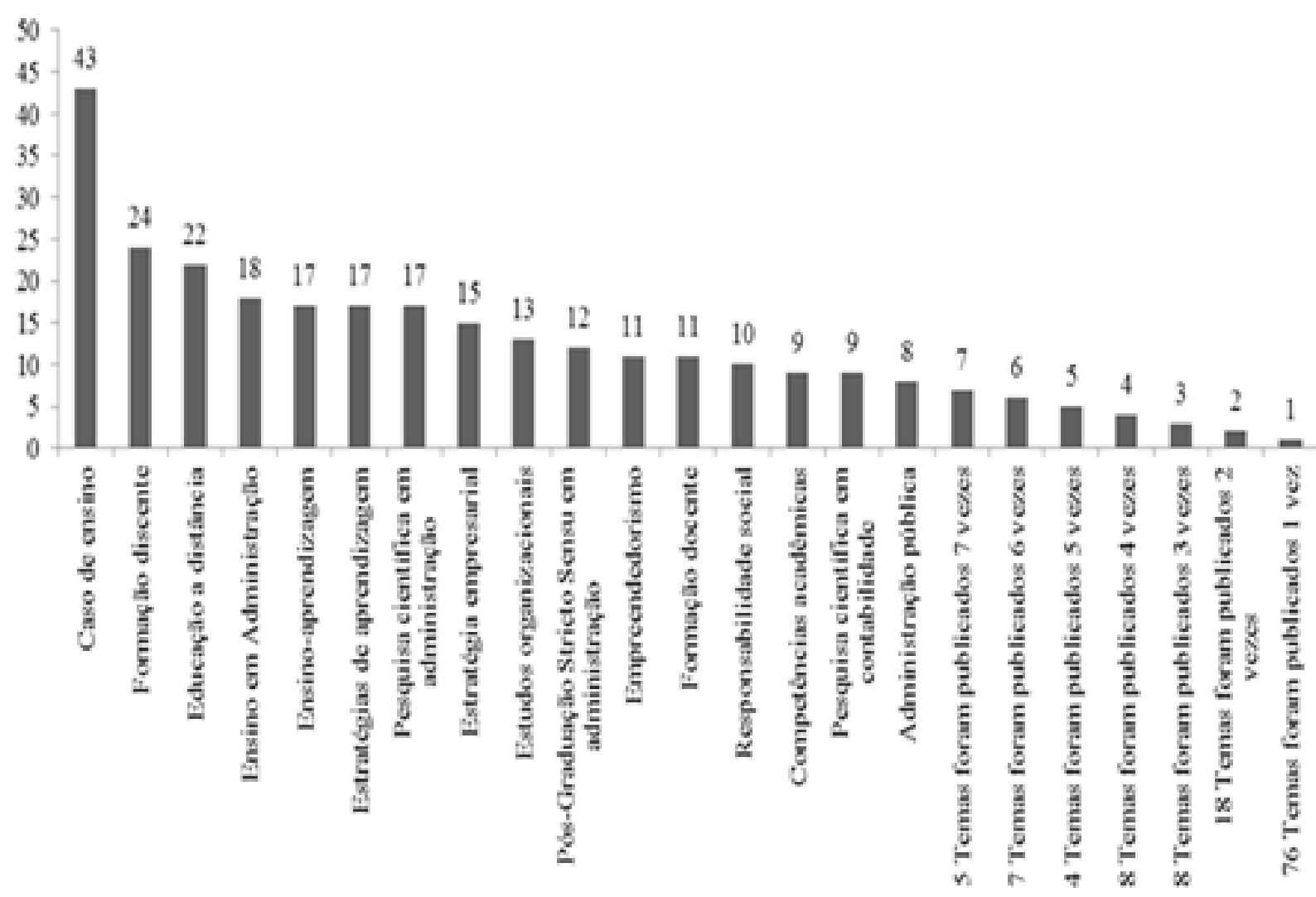


Fonte: Dados da pesquisa

De maneira geral, 16 temas foram publicados de oito a 43 vezes; 32 temáticas foram divulgadas de três a sete vezes; 18 assuntos foram publicados duas vezes; e a grande maioria, 76 temas foram divulgados uma vez cada. Totalizou-se 142 assuntos que foram publicados sobre a área Ensino e Pesquisa em Administração e Contabilidade nos períodos de 2007, 2009, 2011, 2013 e 2015. De maneira geral, os resultados evidenciados nesta seção, mostram que a área do conhecimento em análise tem uma diversidade alargada no que tange a publicação de temas relacionados a ela.

Apesar de muitos temas terem sido divulgados somente uma vez, tal achado se torna fortuito em decorrência de que isso é uma oportunidade e também uma tentativa de aprofundar e difundir ainda mais estes temas na academia, mediante o surgimento de novos estudos, encabeçados por pesquisadores iniciantes e ou seniores, resguardados por seus respectivos grupos de estudos, impactando de maneira direta na colaboração científica entre os autores e suas respectivas IES. Tal ação também acarretará diretamente num alargamento e disseminação dessas novas pesquisas na academia, socializando temáticas poucos publicadas até aqui, no âmbito da área ora analisada, impactando diretamente em seu crescimento e maior difusão na literatura científica brasileira.

Analisando agora a Figura 6.2 manifesta-se a terceira rede twomode deste estudo, que enfoca pesquisadores e temas em conjunto (TOMAÉL; MARTELETO, 2013). Realçam-se assim as temáticas que mais tiveram autores vinculados a elas, impactando em suas respectivas proficuidades: caso de ensino, formação discente, educação a distância, estratégias de aprendizagem, ensino em administração e pesquisa científica em administração. Destas, as seis estão entre as sete mais publicadas na presente investigação. 
Figura 6.2: Rede two-mode (autores e temas)

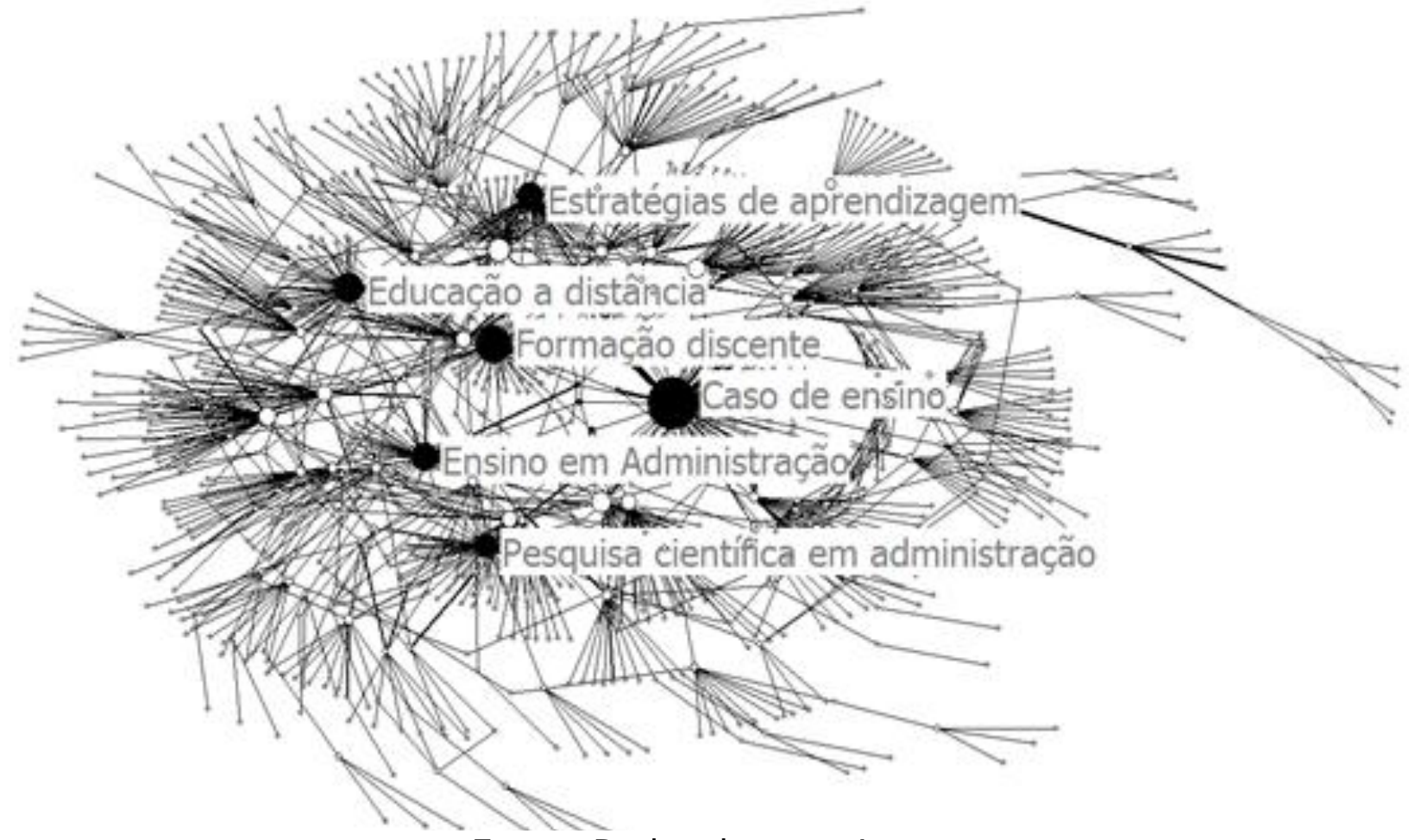

Fonte: Dados da pesquisa

O caso de ensino apresenta-se como umametodologiaexigida por docentes de contabilidade e administração para atender as necessidades estratégicas de aprendizagem na formação discente (LARA et al., 2017). Diante disso, evidencia-se que vêm crescendo sobremaneira a demanda sobre os casos de ensino no panorama brasileiro (FARIA; FIGUEIREDO, 2013). O exemplo disso é a confirmação desta afirmação por meio do destaque deste assunto no presente estudo. Ressalta-se também que, como forma de estimular a disseminação e socialização de casos brasileiros, em 2007, a ANPAD passou a aceitar casos de ensino em seus congressos, como o EnEPQ (FARIA; FIGUEIREDO, 2013), ajudando a explicar também o realce do referido tema nos achados desta pesquisa.

Logo em seguida vem a Formação discente, que é entendida como tema primordial no ensino e pesquisa, pois revela a visão da educação superior como motor de alargamento social (ANDRIOLA; SULIANO, 2015). Seu destaque na referida pesquisa, está atrelado também a sua capacidade de interação com o processo de obtenção de saberes teóricos, técnicos e operacionais (MAIA; CARVALHO-FREITAS, 2015), mediante os cursos de graduação ou pós-graduação das instituições, formando o discente para o mercado de trabalho (MOTTA; QUINTELLA, 2012). Diante disso, versa-se que o tema educação a distância esta muito voltado a formação discente (CASSUNDÉ; CASSUNDÉ JUNIOR, 2012). 
Com isso, ressalta-se que a temática Educação a distância ganha cada vez mais espaço dentro das pesquisas na área de Ensino e Pesquisa em Administração e Contabilidade (CASSUNDÉ; CASSUNDÉ JUNIOR, 2012; SILVA; MELO; MUYLDER, 2015), e essa é uma tendência que deve continuar frente ao eminente avanço do referido temana educação superior (CAVALCANTI JÚNIOR; FERRAZ, 2013), por exemplo, no tocante as estratégias de aprendizagem em cursos a distância (ABBAD; CORRÊA; MENESES, 2010).Diante do contexto observa-se que a temática educação a distância é um assunto visto atualmente como inovação na academia, mesmo diante da evolução sistêmica das pesquisas sobre o citado tema na literatura acadêmica nacional (SILVA; MELO; MUYLDER, 2015).Diante do exposto, vislumbram-se as Estratégias de aprendizagem que são preponderantes para a formação discente (GODOYet al., 2009) em cursos de ensino superior tradicional, a distância e híbridos (MARTINS; ZERBINI, 2014) e pós-graduação.

Diante do contexto ressalva-se a investigação de Odelius e Sena (2009) que descreveram a formação e atuação de grupos de pesquisano meio acadêmico, enfatizandoasestratégias de aprendizagem e desenvolvimento de competências individuais.Os citados autores observaram que as estratégias de aprendizagem nos grupos de estudo ocorrem a partir das dinâmicas de relações que caracterizam o funcionamento destesgrupos, influenciandodiretamente no acesso do conhecimento e dos saberes científicos acumulados (ODELIUS; SENA, 2009).Isto posto, observa-se o impacto positivo das estratégias (processos) de aprendizagem no ensino e na pesquisa nas áreas da ciência sociais aplicadas, como no caso da Administração (NASSIF; GHOBRIL; BIDO, 2007).

Remete-se aos temas Ensino em administração e Pesquisa científica em administração que ficaram também em evidência nesta investigação.Seus respectivos realces vão ao encontro do objetivo do presente estudo, ou seja, o relevo destes temas na colaboração e produção científica do EnEPQ é inerente ao citado evento, visto que, o foco principal deste é adiscussão de temas relevantes da área de Ensino e Pesquisa em Administração e Contabilidade (ANPAD, 2018).E, também, aproeminência dos mencionados assuntos nos achados do presente estudoé expressamediante os trabalhos dos autores:Souza . (2008), Lordsleem \& Araújo (2009), Walter et al. (2009), Espartel et al. (2011), Lourençoet al. (2012), Miranda et al. (2013), Ribeiro (2013), Vendruscolo \& Behar (2014), Bolzan \& Antunes (2015), Schmitz et al. (2015), Ferreira \& Malaquias (2016), Ribeiro (2017).

\section{Considerações finais}


O objetivo deste estudo foi analisar a colaboração e produção científica da área ensino e pesquisa em administração e contabilidade sob a ótica do EnEPQ nos períodos de 2007, 2009, 2011, 2013 e 2015. Para isso, utilizou-se as técnicas de análise bibliométrica (LEITEFILHO, 2008) e de rede social (PESSOA ARAÚjOet al., 2017), sendo que está última, focou-se nas redes de 1-mode e 2-mode (TOMAÉL; MARTELETO, 2013).

Gilberto José Miranda e Roberto Patrus foram os pesquisadores mais prolíferos; a USP foi a IES mais profícua. Os temas mais publicados foram: caso de ensino, formação discente, educação a distância, ensino em administração, ensino-aprendizagem, estratégias de aprendizagem, pesquisa científica em administração, estratégia empresarial, estudos organizacionais e pós-graduação stricto sensu em administração. As redes one-mode, contemplaram a alta centralidade nas redes de coautoria e das IES, salientando o estudioso Gilberto José Miranda e a IESUSP como os atores mais centrais em suas respectivas redes.

As redes two-mode corroboraram com as redes one-mode, enfocando a preponderância e o relevo das instituições e dos temas abordados nesta pesquisa, isto é, as referidas redes 2-mode (autores e IES; e autores e temas) contribuíram para contemplar a envergadura das instituições, e a tendência dos temas publicados na academia, influenciando diretamente para melhor entender e compreender como as redes de colaboração e produção científica da área Ensino e Pesquisa em Administração e Contabilidade são evidenciadas e disseminadas sob a ótica do EnEPQ na literatura científica brasileira.

De maneira geral, as análises evidenciadas no presente estudo,permitiram a identificação dos principais atores individuais (1mode) - (autores, IES e temas) - e emconjunto (2-mode) - autores e artigos, autores e IES, autores e temas -abrangidos no campo de Ensino e Pesquisa em Administração e Contabilidade, bem como a percepção de um alargamentoda referida área no que se refere ao número de artigos divulgados sob a ótica do EnEPQ nos períodos de 2007, 2009, 2011, 2013 e 2015.

Com os resultados da presente pesquisa, acreditou-se contribuir para o desenvolvimento do campo de produção acadêmicano Ensino e Pesquisa em Administração e Contabilidade, no sentido de admitir a identificação de futuras associações entre autores e suas respectivas IES, e, de promover a otimizaçãoda realização dessas associações de modo a expandir a troca de informações/conhecimentos e a construção de saberes científicos no campo em análise.

Além do mais, acredita-se proporcionar com os achados evidenciados na pesquisa para oscampos do saber Ensino e Pesquisa em Administração e Contabilidade, uma agenda de pesquisa que sirva, adicionalmente, como umaferramenta de check-up para os Programas de 
Pós-graduação Stricto Sensu em Administração e Contabilidade e seus respectivos grupos de estudo,acarretando a verificação de seuefeito multiplicador na literatura acadêmica nacional, mediante a publicação de novos estudos em eventos científicos, e, concomitantemente suas divulgações em periódicos acadêmicos das áreas de Administração ou Contabilidade, em suas respectivas linhas de pesquisa, que acomodem os temas relacionados ao Ensino e Pesquisa em Administração e Contabilidade.

O presente estudo limitou-se em investigar a colaboração e produção científica do EnEPQ nos períodos de 2007, 2009, 2011, 2013 e 2015, contudo, é salutar afirmar que tanto a questão de pesquisa, quanto o objetivo do estudo foi respondido e alcançado respectivamente, evidenciando no seu bojo informações contemporâneas acerca da área Ensino e Pesquisa em Administração e Contabilidade, influenciando com isso, de maneira macro, no surgimento de resultados e contribuições alargadas e robustas para melhor entendimento e compreensão da área analisada no contexto acadêmico nacional.

Entretanto, nenhuma pesquisa científica é integralmente acabada, possibilitando assim a replicação da ciência, e, consequentemente o aparecimento de novos estudos que, porventura, serão responsáveis por fomentar, difundir e socializar os conhecimentos e saberes científicos das áreas. Isto posto, realçam-se a seguir, algumas sugestões para estudos futuros: (i) replicar o presente estudo, por meio de uma investigação mais ampla, pegando dois ou mais eventos científicos correlatos ao que foi analisado nesta pesquisa; (ii) realizar um estudo somente com os temas identificados e abordados nesta pesquisa, buscando com isso entender e compreender as nuances que cercam a área ora analisada; (iii) utilizar técnicas análogas a bibliometria, como a cientometria, a informetria dentre outras, para elencar ou aperfeiçoar as informações evidenciadas no presente trabalho; e (iv)performar as técnicas de análise de rede, sobretudo no que se refere as rede two-mode.

\section{Referências}

ABBAD, G. da S.; CORRÊA, V. P.; MENESES, P. P. M. Avaliação de treinamentos a distância: relações entre estratégias de aprendizagem e satisfação com o treinamento. Revista de Administração Mackenzie,v. 11, n. 2, p. 43-67, 2010.

ALMEIDA, C. C. de; GRÁCIO, M. C. C. Produção científica brasileira sobre o indicador "Fator de Impacto": um estudo nas bases SciELO, Scopus e Web of Science. Encontros Bibli: Revista Eletrônica de Biblioteconomia e Ciência da Informação, v. 24, n. 54, p.62-77, 2019. 
ALVARADO, R. U. A Lei de Lotka na bibliometria brasileira. Ciência da Informação, Brasília, v. 31, n. 2, p, 14-20, 2002.

ALVARADO, R. U.; ARANGO, C. R. La red de co-autores en la bibliometria Mexicana. Encontros Bibli: Revista Eletrônica de Biblioteconomia e Ciência da Informação, v. 23, n. 51, p. 74-94,2018.

ALVARADO, R. U. El crecimiento de la literatura sobre la ley de Bradford. Investigación Bibliotecológica, v. 30, n. 68,p. 51-72, 2016.

ANDRIOLA, W. B.; SULIANO, D. C.Avaliação dos impactos sociais oriundos da interiorização da Universidade Federal do Ceará (UFC). Revista Brasileira de Estudos Pedagógicos, v. 96, n. 243, p. 282-298, 2015.

ARAúJO, L. C. de; SANSÃO, J. P. H.; YEHIA, H. C. Influência da lei de Zipf na escolha de senhas. Revista Brasileira de Ensino de Física, v. 38, n. 1, p. 1-14, 2016.

ASSOCIAÇÃO NACIONAL DE PÓS-GRADUAÇÃO E PESQUISA EM ADMINISTRAÇÃO - ANPAD. Apresentação.Disponívelem: http://www.anpad.org.br/ anpad.

BALSAN, L. A. G.; KNEIPP, J. M.; TONIN, S.; COSTA, V. M. F. Os vínculos que o indivíduo estabelece com a organização: uma análise da produção científica brasileira. Revista de Ciências da Administração, v. 18, n. 45, p. 25-37, 2016.

BARBOSA, M. W.; LADEIRA, M. B.; VICENTE, A. de la C.Ananalys is of international coauthor ship networks in the supply chain analytics research area. Scientometrics, v. 111, n. 3, p. 1703-1731, 2017.

BERTERO, C. O.; CALDAS, M. P.; WOOD JR., T. Produção científica em administração de empresas: provocações, insinuações e contribuições para um debate local. Revista de Administração Contemporânea, v. 3, n. 1,1999 .

BOLZAN, L. M.; ANTUNES, E. D. D. O que clamam as vozes dos pesquisadores e sobre o que elas se calam ao abordarem o ensino em administração no Brasil?Revista ADM.MADE, v. 19, n. 3, p. 77-93, 2015.

BUFREM, L.; PRATES, Y. O saber científico registrado e as práticas de mensuração da informação. Ciência da Informação, Brasília, v. 34, n. 2, p. 9-25, 2005.

BUFREM, L. S.; SILVA, H. da F. N.; FABIAN, C. L. S. R. e M.; SORRIBAS, T. V.Produção científica em ciência da informação: análise temática em 
artigos de revista brasileiras. Perspectivas em Ciência da Informação, Belo Horizonte, v. 12, n. 1, p. 38-49, 2007.

BULGACOV, S.; VERDU, F. C. Redes de pesquisadores da área de administração: um estudo exploratório. Revista de Administração Contemporânea, v. 5, n. esp., p. 163-182, 2001.

CÂNDIDO, R. B. et al. Lei de Lotka: um olhar sobre a produtividade dos autores na literatura brasileira de finanças. Encontros Bibli: Revista Eletrônica de Biblioteconomia e Ciência da Informação, v. 23, n. 53, p.01$15,2018$.

CASSUNDÉ, F. R.; CASSUNDÉ JUNIOR, N. o estado do conhecimento sobre educação a distância (EAD) em administração: por onde caminham os artigos? Revista Gestão e Planejamento, v. 13, n. 2,p. 366-380, 2012.

CAVALCANTI JÚNIOR, H. S. B.; FERRAZ, I. N. Uma análise da pesquisa sobre educação a distância nosperiódicos brasileiros de administração (2002 - 2011). Gestão \& Regionalidade, v. 29, n. 85,p. 93-104, 2013.

COMUNELO, A. L. ESPEJO, M. M. dos S. B.; VOESE, S. B. ; LIMA, E. M.Programas de pós-graduação stricto sensuem contabilidade: sua contribuição na formação de professores e pesquisadores. Enfoque: Reflexão Contábil, v. 31, n. 1, p. 07-26, 2012.

CORREIA, A. E. G. C. ; ALVARENGA, L. ; GRACIA, J. C. R. Produção científica: reflexos da avaliação nos programas de pós-graduação em Física. Em Questão, v. 18, n. 3, 2012.

COSTA, F. J. da.Formação em administração na perspectiva do aluno: valor percebido no curso, percepção do prestígio e identificação com a profissão. Revista Ciências Administrativas, v. 14, p. 151-163, 2008.

COSTA, R. S. L. F. da; FONSECA, A. C. P. D. da. A utilização da etnografia na pesquisa em contabilidade. Sociedade, Contabilidade e Gestão, v. 13, n. 1,p. 1-18, 2018.

CRUZ, A. P. C. da; ESPEJO, M. M. dos S. B.; COSTA, F.; ALMEIDA, L. B. de.Perfil das redes de cooperação científica: congresso USP de controladoria e contabilidade - 2001 a 2009. Revista Contabilidade \& Finanças, v. 22, n. 55,p. 64-87, 2011.

ESPARTEL, L. B. ; BASSO, K.; TOMAZELLI, J. B.; CALLEGARO, A. R. C. ; VISENTINI, M. S.Co-autoria em ensino e pesquisa em administração e contabilidade no Brasil: uma década em análise. Revista de Administração Imed, v. 1, n. 1, p. 01-28, 2011. 
FARIA, M.; FIGUEIREDO, K. F. Casos de ensino no Brasil: análise bibliométrica e orientações para autores. Revista de Administração Contemporânea, v. 17, p. 176-197, 2013.

FERREIRA, M. A.; MALAQUIAS, R. F. Ensino em contabilidade: uma análise da produção acadêmica. Revista Eletrônica de Administração (Online), v. 15, n. 1,p. 17-31, 2016.

FERREIRA, M. P.; FALASTER, C. Uma análise comparativa dos fatores de rejeição nos periódicos de diferentes estratos de administração. Revista de Administração Contemporânea, v. 20, n. 4, p. 412-433, 2016.

FERREIRA, M. P. V.; CANELA, R.; PINTO, C. F.; FALASTER, C. D. Coautoria em administração no Brasil: pressões, complementaridades e produtividade. Revista de Administração e Contabilidade da Unisinos, v. 15 , n. 1, p.42-55, 2018.

FESTINALLI, R. C. A formação de mestres em administração: por onde caminhamos? Organizações \& Sociedade, v. 12, n. 35, p. 135-150, 2005.

GODOY, A. S.; ANTONELLO, C. S.; BIDO, D. S.; SILVA, D. da.O desenvolvimento das competências de alunos formandos do curso de Administração: um estudo de modelagem de equações estruturais. Revista de Administração da USP, v. 44, n. 3, 2009.

GOMES, G. S.; LEMES, S. Análise das pesquisas em contabilidade publicadas nos periódicos nacionais. Revista de Contabilidade da UFBA, v. 10, n. 2, p. 103-126, 2016.

GUARIDO FILHO, E. R.; MACHADO-DA-SILVA, C. L.; GONÇALVES, S. A. Organizational institutionalism in the academic field in Brazil: social dynamics and networks. Revista de Administração Contemporânea, v. esp., n. 6, p. 149-172, 2010.

GUIMARÃES, T. de A.; GOMES, A. de O.; ODELIUS, C. C.; ZANCAN, C.; CORRADI, A. A.A rede de programas de pós-graduação em administração no Brasil: análise de relações acadêmicas e atributos de programas. Revista de Administração Contemporânea, v. 13, p. 564-582, 2009.

LARA, F. L. et al. Panorama das publicações nacionais de caso de ensino na área de contabilidade e administração.[Anais.... In: CONGRESSO BRASILEIRO DE CUSTOS, 24. 2017.

LATHABAI, H. H.; PRABHAKARAN, T.; CHANGAT, M. Contextual productivity assessment of authors and journals: a network scientometric approach. Scientometrics, v. 110, n. 2, p. 711-737, 2017. 
LEITE FILHO, G. A.; MARTINS, G. de A. Relação orientador-orientando e suas influências na elaboração de teses e dissertações. Revista de Administração de Empresas, v. 46, n. spe, p. 99-109, 2006.

LEITEFILHO, G. A. Padrões de produtividade de autores em periódicos e congressos na área de contabilidade no Brasil: um estudo bibliométrico. Revista de Administração Contemporânea, v. 12, n. 2,p. 533-554, 2008.

LEMES, D. F.; MIRANDA, G. J. Habilidades profissionais do contador preconizadas pela IFAC: um estudo com profissionais da região do triângulo mineiro. Advances in Scientific and Applied Accounting, v. 7, n. $2,2014$.

LIMA LEITE, F. C. O conhecimento científico tácito na dinâmica da pesquisa: alguns indícios. Data Grama Zero - Revista de Ciência da Informação, v. 8, n. 3, p. 1-31, 2007.

LORDSLEEM, N. L. C.; ARAÚJO, R. M. de.Ensino e Pesquisa em Administração: Um Estudo Bibliométrico de Publicações do EnANPAD (2001-2008). Revista Ciências Administrativas, v. 15, n. 2,p. 356-378, 2009.

LOURENÇO, C. D. da S. ; OLIVEIRA, A. L. de; SILVA, I. C. da; NORONHA, N. S. de; ALVES, R. R.; CASTRO, C. C. de. Produção científica brasileira sobre ensino de administração: 1997-2010. Revista Pensamento Contemporâneo em Administração, v. 6, n. 1, p. 4-22, 2012.

MAIA, A. M. DE C.; CARVALHO-FREITAS, M. N. de. O trabalhador com deficiência na organização: um estudo sobre o treinamento e desenvolvimento e a adequação das condições de trabalho. Revista Eletrônica de Administração, v. 21, n. 3, p. 689-719, 2015.

MARTINS, L. B.; ZERBINI, T. Educação a distância em instituições de ensino superior: uma revisão de pesquisas. Revista Psicologia Organizações e Trabalho, v. 14, p. 271-282, 2014.

MEDEIROS, C. R. de O.; BORGES, J. F.; LEAL, E. A. Administração e contabilidade:mercado de trabalho e espaços curriculares comuns. Administração: Ensino e Pesquisa, v. 10, n. 4, p. 17-33, 2009.

MELLO, C. M. de;CRUBELLATE, J. M.;ROSSONI, L. Dinâmica de relacionamento e prováveis respostas estratégicas de programas brasileiros de pós-graduação em administração à avaliação da capes: proposições institucionais a partir da análise de redes de co-autorias. Revista de Administração Contemporânea, v. 14, n. 3, p. 434-457, 2010. 
MELO, D.; SERVA, M.A agenda do professorpesquisadoremAdministração:umaanálisebaseadanasociologia da ciência. Cadernos EBAPE.BR, v. 12, n. 3, p. 605-632, 2014.

MENDONÇA NETO, O. R. de; RICCIO, E. L.; SAKATA, M. C. G. Paradigmas de pesquisa em contabilidade no Brasil:ENANPAD: 1981 - 2005. [Anais ...], EnANPAD, 2006.

MIRANDA, G. J.; SANTOS, L. de A. A.; CASA NOVA, S. P. de C.; CORNACCHIONE JÚNIOR, E. B.A pesquisa em educação contábil: produção científica e preferências de doutores no período de 2005 a 2009. Revista Contabilidade \& Finanças,v. 24, n. 61, p. 75-88, 2013.

MOMESSO, A. C.; NORONHA, D. P. Bibliométrie ou bibliometrics: o que hápor trás de um termo?Perspectivas em Ciência da Informação, Belo Horizonte, v.22, n.2, p.118-124, 2017.

MOTTA, G. da S., \&QUINTELLA, R. H. A utilização de jogos e simulações de empresas nos cursos de graduação em administração no estado da Bahia. Revista Eletrônica de Administração, v. 18, n. 2, p. 317-338, 2012.

NASCIMENTO, S. do; BEUREN, I. M. Redes sociais na produção científica dos programas de pós-graduação de ciências contábeis do Brasil. Revista de Administração Contemporânea, v. 15, n. 1, p. 47-66, 2011.

NASSIF, V. M. J.,;GHOBRIL, A. N.;BIDO, D. de S. É possível integrar a teoria à prática no contexto de sala de aula? uma resposta através do método seminário revisado através da pesquisa ação em um curso de administração. Revista de Ciências da Administração, v. 9, n. 18,p. 11-34, 2007.

ODELIUS, C. C.; SENA, A. de C. Atuação em grupos de pesquisa: competências e processos de aprendizagem. Revista de Administração FACES, v. 8, n. 4, p. b13-31, 2009.

OLIVEIRA e SILVA, A. B. de; MATHEUS, R. F.; PARREIRAS, F. S.; PARREIRAS, T. S.Análise de redes sociais como metodologia de apoio para a discussão da interdisciplinaridade na ciência da informação. Ciência da Informação, Brasília, v. 35, n. 1,p. 72-93, 2006.

PARENTE, T. C.; FISCHER, A. L. A relação entre recursos humanos e sustentabilidade como tema emergente: uma análise bibliométrica. Revista Alcance, v. 21, n. 3, p. 398-421, 2014.

PARREIRAS, F. S.; OLIVEIRA SILVA, A. B. de; MATHEUS, R. B.; BRANDÃO, W. C. RedeCI: colaboração e produção científica em ciência da informação 
no Brasil. Perspectivas em Ciência da Informação, Belo Horizonte, v. 11, n. 3, p. 302-317, 2006.

PESSOA ARAÚJO, U. et al. Trajetória e estado corrente da sociometria brasileira. Revista Hispana para el Análisis de Redes Sociales, v. 28, n. 2, p. 97-128, 2017.

PIERANTI, O. P. A metodologia historiográfica na pesquisa em administração: uma discussão acerca de princípios e de sua aplicabilidade no Brasil contemporâneo. Cadernos EBAPE.BR, v. 6, n. 1, p. 1-12, 2008.

PINHEIRO, D. C. O estado da arte da produção científica em economia solidária. Administração Pública e Gestão Social, v. 8, n. 2, p. 95-103, 2016.

QUINTELLA, R. H. Encontro nacional da Anpad x meeting of AOM:lições, questionamentos e especulações. Revista de Administração de Empresas, v. 43 , n. 2 , p. 107-115, 2003.

RIBEIRO, H. C. M. Características da Produção veiculada na Revista de Educação e Pesquisa em Contabilidade no período de 2007 a 2012. Revista de Educação e Pesquisa em Contabilidade, v. 7, n. 4,p. 424-443, 2013.

RIBEIRO, H. C. M. Dez anos da produção científica da área temática educação e pesquisa em contabilidade publicada na AnpCONT. Revista Mineira de Contabilidade,v. 18, n. 3, p. 65-78, 2017.

RIBEIRO, H. C. M.; SANTOS, M. C. dos. Perfil e evolução da produção científica do tema governança corporativa nos periódicos Qualis/Capes nacionais: uma análise bibliométrica e de redes sociais. Contabilidade, Gestão e Governança,v. 18, n. 3, p. 04-27, 2015.

ROSSONI, L. ; GUARIDO FILHO, E. R. Cooperação entre programas de pós graduação em graduação em administração no Brasil: evidências estruturais em quatro áreas temáticas. Revista de Administração Contemporânea, v. 13, n. 3, p. 366-390, 2009.

ROSSONI, L.; GUARIDO FILHO, E. R. Cooperação interinstitucional no campo da pesquisa em estratégia. Revista de Administração de Empresas, v. 47, n. 4, p. 74-88, 2007.

ROSSONI, L. ; HOCAYEN-DA-SILVA, A. J. Cooperação entre pesquisadores da área de administração da informação: evidências estruturais de fragmentação das relações no campo científico. Revista de Administração da USP, v. 43, n. 2, p. 138-151, 2008. 
SAMPAIO, R. B.; SACERDOTE, H. C. de S.; FONSECA, B. de P. F.; FERNANDES, J. H. C. A colaboração científica na pesquisa sobre coautoria: um método baseado na análise de redes. Perspectivas em Ciência da Informação, Belo Horizonte, v. 20, n.4, p.79-92, 2015.

SANTOS, G. E. de O.; REJOWSKI, M. Comunicação científica em turismo no Brasil: análises descritivas de periódicos nacionais entre 1990 e 2012. Revista Brasileira de Pesquisa em Turismo, v. 7, n. 1, p. 149-167, 2013.

SERRA, F. A. R.; FERREIRA, M. A. S. P. V.; CUNHA, J. A. C. da. Comentário editorial escolha do periódico para submissão do seu artigo. Revista Ibero-Americana de Estratégia, v. 16, n. 1, p. 1-7, 2017.

SERVA, M. The contribution of the international colloquium on epistemology and sociology of science to the administration field in Brazil. Cadernos EBAPE. BR, v. 14, n. 1, p. 1-11, 2016.

SILVA, A. dos S.; CARVALHO NETO, A. Uma contribuição ao estudo da liderança sob a ótica weberiana de dominação carismática. Revista de Administração Mackenzie, v. 13, n. 6, p. 20-47, 2012.

SOUSA, E. da S.; RODRIGUES JÚNIOR, M. S.; COELHO, A. C. Abordagens morfológica e metodológica na produção científica sobre ensino e pesquisa em administração. [Anais...],SemeAd, 20. 2017.

SOUZA, F. C. de; ROVER, S.; GALLON, A. V.; ENSSLIN, S. R.Análise das IES da área de ciências contábeis e de seus pesquisadores por meio de sua produção científica. Contabilidade Vista e Revista, v. 19, n. 3,p. 15$38,2008$.

SCHMITZ, T.; SANTOS, V. dos; BEUREN, I. M.; FAVERI, D. B. de.Conversão dos trabalhos da área contábil apresentados em congressos para publicações em periódicos. Revista Universo Contábil, v. 11, n. 2,p. 128-152, 2015.

SILVA, M. P. D.; MELO, M. C. de O. L.; MUYLDER, C. F. de. Educação a distância em foco: um estudo sobre a produção científica brasileira. Revista de Administração Mackenzie, v. 16, n. 4, p. 202-230, 2015.

TEIXEIRA, M. L. M.; IWAMOTO, H. M.; MEDEIROS, A. L. Estudos bibliométricos (?) em administração: discutindo a transposição de finalidade. Administração: Ensino e Pesquisa,v. 14, n. 3, p. 423-452, 2013.

TOMAÉL, M. I.; MARTELETO, R. M. Redes sociais de dois modos: aspectos conceituais. TransInformação, v. 25, n. 3, p. 245-253, 2013. 
TOMOMITSU, H. T. A.; CARVALHO, M. M. de; MORAES, R. de O. A evolução da relação entre a gestão de projetos e a gestão do conhecimento: um estudo bibliométrico. Gestão \& Produção, p. 1-16, 2017.

URBIZAGASTEGUI, R. A produtividade dos autores sobre a Lei de Lotka. Ciência da Informação, Brasília, v. 37, n. 2,p. 87-102, 2008.

VENDRUSCOLO, M. I.; BEHAR, P. A. Educação e pesquisa em contabilidade: estado da arte do congresso USP de controladoria e contabilidade do período de 2004 a 2012. Revista Ambiente Contábil, v. 6, n. 1, p. 83-98, 2014.

WALTER, S. A.; CRUZ, A. P. C. da; ESPEJO, M. M. dos S. B.; GASSNER, F. P.Uma análise da evolução do campo de ensino e pesquisa em contabilidade sob a perspectiva de redes. Revista Universo Contábil, v. 5, n. 4,p. 76-93, 2009. 